\title{
From Neophyte to Experienced Facilitator: an Interactive Blended-Learning Course for Graduate Teaching Assistants in Hong Kong
}

\author{
Kai-Pan Mark* \\ City University of Hong Kong, Hong Kong \\ E-mail:markkp@cityu.edu.hk

\section{Dimple R. Thadani} \\ City University of Hong Kong, Hong Kong \\ E-mail: dimplet@student.cityu.edu.hk

\section{David Santandreu Calonge} \\ City University of Hong Kong, Hong Kong \\ E-mail: lsdavids@cityu.edu.hk
}

\section{Cecilia F.K. Pun}

City University of Hong Kong, Hong Kong E-mail: fungkpun@student.cityu.edu.hk

\section{P.H. Patrio Chiu}

City University of Hong Kong, Hong Kong

E-mail: phchiu@ cityu.edu.hk

*Corresponding author

\begin{abstract}
Faculty training in tertiary institutions around the world is receiving increasing attention as it plays a significant role to ensure high quality learning and teaching practices in constantly changing multi-cultural education backgrounds. In the case of Graduate Teaching Assistants (GTAs), designing an effective training course to help them deliver content interactively, using student-centered strategies and approaches in a second language (in this case English), becomes critical. Rather than training GTAs in procedural and declarative knowledge (knowledge of facts and processes), a shift in emphasis to functioning knowledge, e.g., classroom management techniques, course design, formative and summative peer review, presentation skills, is the focus of this intensive course, which is heavily supported by two educational etechnologies, Echo360 Lecture Capturing System and an asynchronous Discussion Board, hosted under the Blackboard (Bb) Course Management System. Adopting an ethnographic approach in which all the researchers have co-taught this course for at least two years, this paper chronicles the effort of using Echo360 and $\mathrm{Bb}$ Discussion Board to support the delivery of course content and assessment tasks that yields reflective practices. Achievement of
\end{abstract}


learning outcomes is evaluated through the use of multiple measures: reflections of course attendees, researchers' direct observation, and statistics provided by the Learning Management System. Results are very encouraging in terms of significant improvement of graduate students' presentation skills and self-reflective practices facilitated by Echo360 and Discussion Board.

Keywords: e-Learning Technologies; Graduate Teaching Assistants; Lecture Capture; Online Discussion Board

Biographical notes: Kai-Pan Mark is a locally-trained Ph.D. candidate in the Department of Information Systems, City University of Hong Kong, as well as a Teaching Assistant in Office of Education Development and General Education in the same university. He is currently the Administrative Assistant to the President of IEEE Education Society and the vice-chair of IEEE Education Society Hong Kong Chapter. Kai-Pan's research interest is on the behavioral aspects of different stakeholders in e-Learning systems addressing issues on habitual behavior formation through personalization and IT artifact design. His work has been published in numerous journals, international conference proceedings and book chapter. $\mathrm{He}$ is also active in applying educational technologies to bring in engaging learning experience for undergraduate and postgraduate students. His teaching areas include technicaloriented Computer Science subjects, business-oriented Information Systems subjects and educational development courses. He is the recipient of IEEE Education Society Student Leadership Award 2010, and is also a 2010 FIE New Faculty Fellow.

Dimple. R. Thadani is a PhD Candidate at the City University of Hong Kong. Her research interests include social computering technology, and online game collaborative learning and leadership.

David Santandreu Calonge is Associate Director, Office of Education Development and General Education (EDGE), City University of Hong Kong. $\mathrm{He}$ taught previously Languages/Corporate Communication courses and coordinated the French and Spanish Section. David is an Associate of the Chartered Institute of Linguists and Institute of Translation and Interpreting. $\mathrm{He}$ has published six books and various articles or translations on business, language, economics and teaching strategies. David was awarded the City University of Hong Kong Teaching Excellence Award in 2003/2004 for is well-rounded approach to Teaching and Learning. He is also the recipient of the prestigious International Award for Innovative use of Technology in Teaching and Learning conferred in the USA in 2005 and was nominated for the Ernest L. Boyer International Award for Excellence in Teaching, Learning and Technology 2005. David has been appointed as a Chevalier dans l'Ordre des Palmes Académiques ("Knight in the Order of Academic Palms") by the French Prime Minister and Minister of National Education. He is also one of only six French nationals from 350 candidates around the world, to be awarded the "Trophées Sénat de la présence française à l'étranger 2008" (International Trophies of the French Abroad) by the French Senate. David is the first international recipient of the Kappa Delta Pi (International Honor Society in Education) Teacher of Honor Award (2009).

Cecilia F.K. Pun is a co-tutelle PhD student in the Department of Chinese, Translation and Linguistics in the City University of Hong Kong, and the Department of Linguistics in the University of Sydney, working on the development of academic writing in tertiary settings. Her research interest includes Systemic Functional Linguistics, text analysis, corpus linguistics and academic writing. 
P.H. Patrio Chiu is an Education Development Officer at the City University of Hong Kong - Office of Education Development and General Education (EDGE). He received his Ph.D., M.Eng. and B.Eng., all in Electrical Engineering, in 2006, 2002 and 2000 respectively from McGill University, Canada. He has served in the Canadian Space Agency and has taught Physics and Engineering at University and College levels. Currently, he is involved in teaching and learning development programs at CityU HK. He is a member of IEEE.

\section{Introduction}

Full time research students in Hong Kong play an important role in supporting learning and teaching activities of undergraduate, and sometimes taught postgraduate programs. As a recipient of studentship or any kind of stipends, a full-time research student needs to undertake teaching duties in his/her department as a condition of financial subsidy. These academic duties include supervision of laboratory sessions, conducting tutorial sessions, assessing and providing feedback to student assignments, and often supporting General Education courses.

Generally, first-year research students, together with senior research students, are assigned teaching responsibilities, usually as Teaching Assistants or demonstrators in most cases unsupervised or without undergoing any formal training in active learning strategies, class management and assessment. In the case of first-year research students, a common challenge often expressed when surveyed is the lack of prior instructional experience and guidance on classroom teaching (Bomotti, 1999), and the feeling that balancing the complex role of teacher and student is difficult (Rubin, 1993). This situation is particularly exemplified by students from the Chinese Mainland (the majority of our research student/ GTA population at universities in Hong Kong), with Mandarin Chinese as their mother tongue, who usually perceive teaching as solely 'delivery of content' (Menges \& Rando, 1989). At City University of Hong Kong for instance, the majority of full time research students $(93.54 \%)$ is from the Chinese Mainland while most of the undergraduate student population (94.0\%) is Cantonese-speaking local natives. Throughout this course (in-class and online activities), non-local research students are encouraged to reflect and compare Hong Kong and Mainland teaching styles, peer - to - peer and student-instructor class interactions, cultural values and the challenges of using English as a medium of instruction (EMI). This is evidenced by a reflection submitted by one of the research students:

"After taking six lectures of this course, my teaching values, beliefs and goals are somewhat changed when comparing them with what I thought. Previously, I believed that teaching is delivering knowledge based on the understanding of the lecturer. Now my beliefs for teaching is encouraging and involving students to 'learn knowledge' and the way of learning from their perspectives."

The purposes of this paper are to (1) chronicle the effectiveness of the synchronous and asynchronous use of two e-learning technologies, Echo360, an institutional-wide automatic lecture capturing system, and discussion boards to engage graduate students in class and online, especially our Suzhou (Mainland China) students in our off-shore campus, and (2) evidence how these two technologies facilitate reflective practice in learning and teaching. An ethnographic approach is used in the research in which the researchers have been teaching this course for at least four cohorts (280 
students). This ensures that all the researchers have complete membership in the ethnographic site (Watt \& Jones, 2010), and understand the values, beliefs and philosophy in this in-service training course for Graduate Teaching Assistants.

\section{Related Works}

\subsection{Lecture Capture: Origins and Development}

The technology adopted in lecture capture is not a breakthrough innovation. Dated back to the 1990s, there have been cases involving development of lecture capture prototypes for teaching and learning in Higher Education institutions e.g., Abowd (1999). Generally, research on lecture capture has been focusing, in the past decade, on the technical domain and its improvement, using the Design Science (Hevner, March, Park, \& Ram, 2004) approach. For example, Abowd (1999) attempted to design and develop a lecture capturing system using a typical software development approach involving system analysis and design, prototype construction and user evaluation. Yoshida, Tada, \& Hangai (2005) also developed an automatic keyword index algorithm and later performed student evaluation on the usefulness and effectiveness of the algorithm.

Due to (a) different technical constraints and (b) doubts over its effectiveness in fostering reflective practice, lecture capture systems have not been widely adopted in institutional contexts. Mark, Vogel \& Wong (2010) postulated that networking constraint is a main bottleneck to prohibit its further diffusion. Until recently, it was impossible for instance to find a stable network, cable or wireless, with bandwidth high enough to support the multimedia content at an affordable subscription fee. Mobile devices, on the other hand, were too slow and expensive for users, although they always play a critical role to re-access (anytime/anywhere) the lecture capture content. Rapid diffusion of cheap broadband networks since the early 2000s enables lecture capture systems to overcome original technical constraints and be fully institutionalized; large-scale institutionalized usage of a lecture capturing system is still at the emerging stage however (see b) above). Llamas-Nistal, Caeiro-Rodríguez, \& Castro (forthcoming) confirmed, in a recent survey, that video functionalities are the least adopted module in the Learning Management System.

Tsang, Mark \& Vogel (2010) reported a qualitative survey on 15 postgraduate students who took a teaching development course supported by a lecture capturing system (LCS). The LCS was first perceived by students as a reliable archive source, allowing them to review content repeatedly and revise accordingly, and by teachers as a way to reduce the administrative workload (overlapping/redundant questions) that would have normally occurred without such a system in place. Through more systematic and prolonged use of the LCS, interviewees responded that it also serves as an effective tool for reflection on their teaching practice. In practice, lecture capture videos can also provide an interactive channel for senior faculty, education development staff and novice teachers to discuss educational issues, share their experience and expertise and reflect on their instructional practices. Enthusiastic teachers, seeking class management improvements, can also watch their own teaching videos to see students' in-class verbal and non verbal reactions as well as student-student interactions (group work/think-pairshare, one-minute papers, etc.) or identify areas or parts of the lecture to ameliorate. Frequent deliberate usage of this system can eventually become an habitual 'behavior of 
system usage' (Ortiz de Guinea \& Markus, 2009) and promote continuous self-reflection and improvement in teaching quality.

The literature on the pedagogical adoption of lecture capturing systems focuses mainly on the delivery of short term procedural/ declarative knowledge (e.g., a standard one semester course) which involves neither functional skills delivery nor metacognition or long-term reflection. Brotherton \& Abowd (2004) present for instance a longitudinal analysis over a prototype developed by Abowd (1999). Continued reflective practice was not achieved as evidenced in the findings, "The captured notes are mostly used to review lectures shortly after they occurred and for exam cramming purposes only." Brotherton \& Abowd (2004) (p.153). Mark \& Vogel (2009) present some suggestions on how to extend system functionalities to achieve long-term continued use of a course management system. This might be the first step to provide students with a personalized system that facilitates reflective learning. However, the critical issue on how reflective practices can be incubated through lecture capturing in teaching and learning activities is still not addressed in the literature.

\subsection{Discussion Board}

The significant difference between discussion boards and other online collaboration tools is its asynchronous nature (Horton, 2000). Asynchronous discussion allows instructors and students to post a thread anywhere and anytime so interactions are extended beyond class hours and virtually into any physical locations (Yip \& Mark, 2007). In common Confucian culture, especially among Chinese learners, discussion boards have an advantage over other online collaboration tools simply because They are asynchronous in nature. Chinese learners consider themselves as respectful listeners (Brooks, 1997; Gan, 2009), are generally shy and are afraid to make mistakes (loss of face) in a classroom setting (Flowerdew, 1998; Hu \& Fell-Eisenkraft, 2003). On the discussion board, learners have plenty of time to polish and rephrase before posting a thread, which removes the fear of making incorrect responses. The reverse for instructor is also true as some instructors feel more comfortable to compose and refine their responses to students' postings instead of a real time synchronous interaction (Mazzolini \& Maddison, 2007). Therefore, discussion board supplements classroom discussion in the virtual space by increasing engagement and participation from usually quiet and reserved students $(\mathrm{Ku}$, Pan, Tsai, Tao, \& Cornell, 2004). The asynchronous nature, however, also induces challenges on the instructor's side. Outgoing instructors may find it challenging and sometimes frustrating to interact asynchronously in writing on [classroom active learning strategies], in a virtual medium without 'getting the whole picture' (students' non verbal communication) (Mazzolini \& Maddison, 2007).

One research area in online assessment is to assess how learning outcomes are related to discussion board participation. Having objective measurement on online discussion board participation is often difficult. Traditionally, the number of posts in a discussion board is the quantitative index of online discussion participation. Harasim (1993) defines a post as a message or a comment a student wrote, or replied to, in a discussion board. Cheng, Paré, Collimore, \& Joordens (2011), however, argue that the number of posts is not the only objective measure to online participation because it does not consider the frequency of reading feedback, which is an essential learning activity in reflective learning, from peers and instructors. The number of visits and the duration (time spent during each visit) should therefore be considered when determining the level of online discussion participation. 
Instructor's moderation on discussion boards has a strong influence on students' participation. Mazzolini \& Maddison (2003) concluded that the ways in which instructors post to discussion boards can influence students' discussions and perceptions: frequent postings by an identified instructor does not necessarily lead to more student postings, neither does the invisible online presence of the instructor. Yeh (2005) reported an interesting study on how students reacted in online discussion with instructor's constructive feedback. On the one hand, students were found to have more active online collaboration and participation when they were informed that instructors would participate and comment on the posts. On the other hand, students were found to have minimal collaboration even though instructors participated and commented on the discussions when they were not informed about instructors' participation in advance.

The role of socialization and purpose on discussion boards also plays a role in influencing students' online participation experience. In a longitudinal study of discussion board usage, Williams \& Pury (2002) found that only a minority of students perceived online discussion as 'fun', while some even categorized it as a 'total waste of time'. The effect of socialization is further explained in Cotterill et al. (2010), who postulates that students prefer to discuss social or personal issues on the private domain and tend to separate academic social networks from the private social network. Therefore, the best practice to facilitate collaborative learning through discussion board is to integrate both social and purposeful instructional interaction online (Martyn, 2005).

\subsection{Ethnography Site: SG8001 at City University of Hong Kong}

Given the number of new programmes being launched and the classes that are currently being taught at City University of Hong Kong, with a predicted sharp increase of students with the launch in 2012 in Hong Kong of the 4-year degree curriculum and the urgent need to launch dozens of General Education courses to cater to them, the fact that faculty's time is constantly squeezed as they are under pressure to fulfill increasing research demands, since universities compete now in the world research arena, greater emphasis needs to be placed on preparing postgraduates for the teaching profession.

To provide GTAs with instructional training, the Office of Education Development and General Education (EDGE) started to offer the course "SG8001: Teaching Students: First Steps", a one-credit pass/fail compulsory course for all research postgraduates since Semester B 2007/08. The course aims to prepare participants for their limited facilitating role while they are research students; it provides an introduction to the basic theoretical knowledge on teaching and practical skills training required of them before they begin to take up teaching responsibilities at the University. Course participants are required to deliver a 10-minute mock teaching session by the end of the course. Individual feedback is given by the course instructors in the form of small group debriefing and personalized written comments.

The course adopts Outcome Based Teaching and Learning (OBTL) principles in course design and makes extensive use of e-learning features, e.g., discussion board, wiki, Wimba voice tools, Echo360 lecture capturing technology and e-portfolio inside and outside the classroom. E-learning technology is heavily deployed in SG8001 for two reasons. First, SG8001 is delivered in both Hong Kong campus and the satellite Suzhou Campus (Mainland China) but the instructors are all based at the Hong Kong campus. Elearning technology is therefore essential to connect students and instructors beyond classroom contact hours as they are physically apart from each other. Second, SG8001 is designed to be comprehensive but intensive and only involves 5 face-to-face sessions. The use of E-learning technologies are indispensible parts of this course in a number of 
ways, i.e. (1) encouraging participation in teaching and learning activities, (2) enabling collaboration between peers and instructors, (3) providing fast and constant feedback during assessment, and (4) facilitating reflective learning.

Gandell, Weston, Finkelstein, \& Weiner (2000) categorized the extent of web use according to the importance and relevance of the learning goals. The use of the web in our course falls into the "central" category as it is relevant and necessary to achieve most learning goals in the course, and would have a substantial impact on student learning. Using the Blackboard Learning Management System as the University's web-based elearning platform, the course has utilized many Blackboard add-on features, especially applications supporting collaboration (e.g., discussion board) and multimedia functions (e.g., lecture capturing system), to achieve the aforementioned goals. Thus, the decrease in physical contact hours was off-set by the internet-based communication. The Instructors and Teaching Assistants used interactive tools such as e-mail, Skype, blackboard announcements and online posts to inform students about interaction opportunities, as proposed by Yeh (2005) to foster collaborative learning between students.

Specifically, session 4 of SG8001 focuses on presentation skills ,applied to the Assessed Teaching and Learning Activity in Session 5, where students select an academic topic of their choice, close to their personal interests (Malone \& Lepper, 1987) and present it to their peers who will evaluate their work (summative peer-review) nearly instantaneously. Oral presentations are video captured using Echo 360 so that students can self-evaluate their own performance; peers give their feedback using specificallydesigned rubrics, instructors provide a personalized report to help students gauge their facilitation skills, and put them in a real-case scenario (on-the-job: facilitating a session/observing/evaluating). This experience undoubtedly helps them to (a) conduct a class in a formal but collegial atmosphere, (b) think of their own teaching philosophy and construct their reflective portfolio and (b) assess their students' performance and/or colleagues (Peer Review) in their future academic career.

\section{Research Hypotheses/ Postulations}

This study was undertaken to identify the impact of use of e-learning tools -Echo360 and discussion board on learning performance and reflective practice. Three research postulations were developed for testing. Gauci, Dantas, Williams, \& Kemm (2009) reported a study on the relationship between anticipation of electronic response systems and assessment results. Examination performance among those who participated most frequently with the electronic response systems in lectures was reported to be positively associated with prior achievements in related physiology courses. A possible explanation is through collective responses from electronic response systems, students can relate their performance to the rest of the class. This comes to our first postulation:

P1: Active online participation is positively associated with better achievement of the learning outcomes;

Marxa, Blumenfeld, Krajcik, \& Soloway (1998) asserted that innovative educational technologies can provide "visions of enactments of innovations along with teachers' reflections". In this aspect, video cases are reported as a good medium to address needs (e.g., student engagement, classroom management, classroom discussion facilitation) of pre-service teachers (Kurz, Batarelo, \& Middleton, 2009). This comes to our second postulation: 
P2: $\quad$ Echo360 fosters self-reflection in teaching practices;

The perception of teachers and peers' presence in an online community is a critical factor in the success of an online learning community (Richardson \& Swan, 2003), and students with high online social presence are reported to score higher in terms of perceived learning and perceived satisfaction with the instructor and the course. Finally, we postulate that:

P3: Discussion boards that integrate social and purposeful instructional interaction facilitate learning and reflective practices.

Our postulations were tested quantitatively with system access logs and summative assessments results, and qualitatively with analysis of reflective portfolios and feedback collected from Learning Experience Questionnaires.

\section{Research Method}

To ascertain the impact of Echo360 and discussion board on facilitating reflective practice in teaching and learning as well as improvement of learning outcomes, a multimethodological approach was adopted to collect evidence on how Echo360 and discussion board facilitate GTAs' reflective practice. Direct observation from the researchers, qualitative analysis of students' reflective portfolios, and quantitative analysis of online participation and assessment results were adopted as data collection methods. The theme of our research approach is to determine how Echo360 and discussion board facilitate reflective practice among Graduate Teaching Assistants in our SG8001 course.

\section{Quantitative Design}

To test our first postulation, data were pooled from the Blackboard Learning Management System. Students who were enrolled in the course in the academic year 2010/2011 semester A is required to use blackboard learning management system as an e-learning platform. The system is able to record online activities of individual students.

\section{Participants}

The population of the study consisted of a total of 101 graduate students in two batches of graduate teaching assistants training course (SG8001-01; SG8001-02) during the academic year 2010-2011. Each class was taught by the same instructor, provided with the same teaching materials.

Table 1. Summarizes the demographic information of the participants.

\begin{tabular}{|c|c|c|}
\hline Batch & SG8001 -01 (Hong Kong) & SG8001 -02 (Hong Kong) \\
\hline Number of students & 47 & 54 \\
\hline Demographics & $\begin{array}{l}76 \% \text { College of Science and } \\
\text { Engineering; } 12 \% \text { College of } \\
\text { Liberal Arts and Social } \\
\text { Science; } 2 \% \text { College of } \\
\text { business }\end{array}$ & $\begin{array}{l}59 \% \text { College of Science and } \\
\text { Engineering; } 29 \% \text { College } \\
\text { of business; } 6 \% \text { College of } \\
\text { Liberal Arts and Social } \\
\text { Science } ; 6 \% \text { others }\end{array}$ \\
\hline
\end{tabular}




\section{Measurement}

\section{Online Participation}

Online participation is measured by 2 indicators - the total number of [access to the blackboard course site] and the number of [online posts]. The duration of each visit by each student was reviewed to ensure relevant participation.

\section{Learning outcome}

Learning outcome of the course is measured by the overall score obtained by the students at the end of the course.

\section{Data Analysis and Results}

In this study, Partial Least Square (PLS) Regression technique is used to investigate the impact of online participation on learning outcomes. PLS technique is chosen by the Teaching Team, for path modeling because it can handle sample sizes of less than 200 (Chin, 1995). PLS technique is a second generation technique that could handle unobserved latent variables and accounts for measurement errors in the estimation process (Chin, 1994). PLS selects a path-dependent model that explains the most variance within each path based on t-values. The model (see figure 1) was examined by using SmartPLS 2.0 software. Demographic information such as major is controlled.

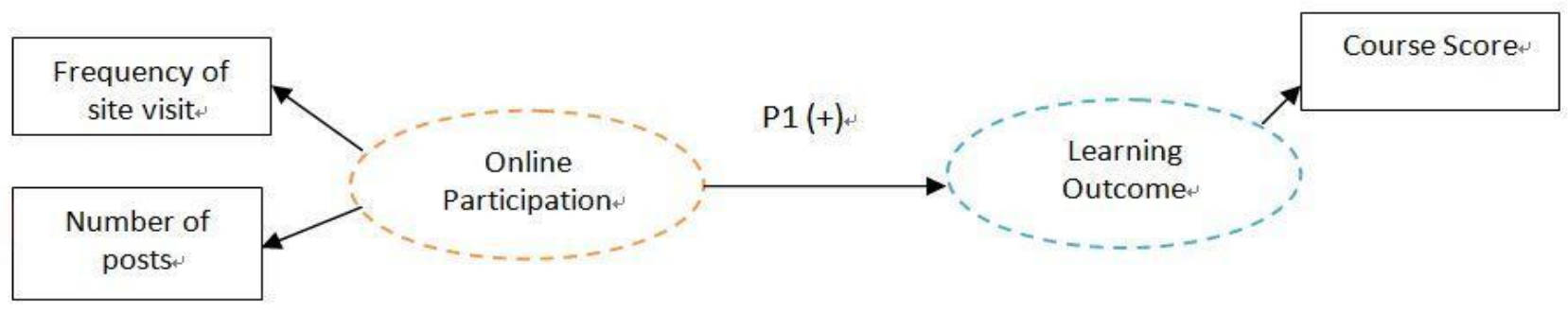

Figure 1. Model of the impact of online participation on learning outcome

\section{PLS Analysis - Measurement Model}

Both the convergent validity and discriminant validity of our measure was examined. Convergent validity indicates the extent to which the measuring items of a scale should be related. A composite reliability (CR) of 0.70 or above and an average variance extracted (AVE) of 0.50 or above are the recommended level of convergent validity (Fornell and Larcker, 1981). Table 2 summarizes the item loadings, composite reliability, and average variance extracted of the measuring items for each batch. Learning outcome is a single item construct so the value for factor loading, composite reliability and AVE are 1.00. Thus, all items have significant path loadings at the 0.01 level and they all fulfill the recommended levels of the composite reliability and average variance extracted. 
Table 2. Convergent validity of measures

\begin{tabular}{|llll|}
\hline Online Participation & & SG8001-01 & SG8001-02 \\
\hline & Frequency of site visit & 0.792 & 0.812 \\
\hline & Number of posts & 0.968 & 0.922 \\
\hline Composite Reliability & & 0.877 & 0.860 \\
\hline Average Variance Extracted & 0.782 & 0.755 \\
& & & \\
\hline
\end{tabular}

Discriminant validity involves checking whether the measuring items measure the construct in question or other related constructs. Discriminant validity is examined with the squared root of the average variance extracted for each construct higher than the correlations between it and all other constructs. As shown in Table 3, each construct shares greater variance with its own block of measures than with the other constructs representing a different block of measures. Overall, the results provide strong empirical support for the convergent validity and discriminant validity of the measures of our research model.

Table 3. Discriminant validity of measures

\begin{tabular}{|lll|}
\hline SG8001-S01 & Online Participation & Learning Outcome \\
\hline Online Participation & 0.884 & \\
\hline Learning Outcome & 0.294 & 1.00 \\
\hline SG8001-S02 & Online Participation & Learning Outcome \\
\hline Online Participation & 0.870 & \\
\hline Learning Outcome & 0.415 & 1.00 \\
\hline
\end{tabular}

PLS Analysis - Structural Models

Figures 2 and 3 present the results of our study with the overall explanatory power, the estimated path coefficients, and the associated t-value of the paths for the two batches of students. Tests of significance of all paths were performed using the bootstrap resampling procedure.

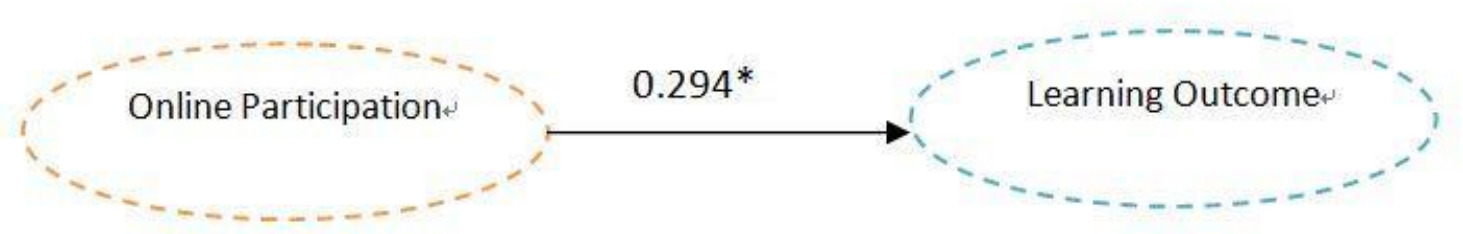

Figure 2. PLS result of Batch 1 (Significance level : *=0.05; $* *=0.01 ; * * *=0.001$ ) 
Figure 2 shows the structural model of the first batch of students (SG8001-S01). The structural model explains $8.6 \%$ of the variance. Online participation $(\beta=0.294$, $\mathrm{t}=2.465$ ) has a significant positive effect on learning outcome.

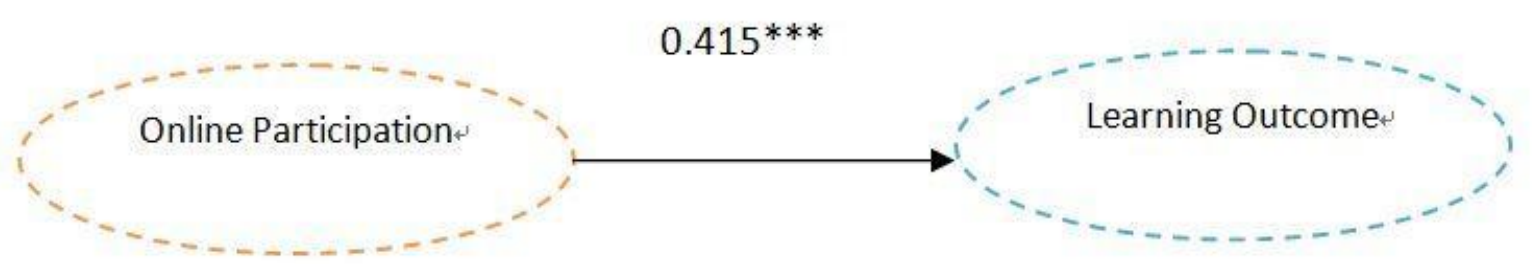

Figure 3. PLS result of Batch 2 (Significance level : *=0.05; **=0.01; ***=0.001)

Figure 3 shows the structural model of the second batch of students (SG8001S02). The structural model explains $17.2 \%$ of the variance. Online participation $(\beta=$ $0.415, \mathrm{t}=4.002$ ) exhibit significant positive impact on learning outcome.

\section{Lecture Capture System: Channel of self-reflection}

Qualitative evidence of P2: Echo360 is a good channel of self-reflection in teaching practices is collected through the end-of-course reflective portfolios and feedback from Learning Experience Questionnaires (LEQ).

In summary, Echo360 is useful in terms of teaching development. In a teacher training course for new faculty and new graduate teaching assistants, lecture capture videos provides a channel for senior faculty and education development staff to reflect together with new teachers on their teaching performance. Enthusiastic and reflective practitioners also watch their own teaching videos to see students' reactions in the classroom. This is reflected in the three quotes submitted by students:

"Echo 360 is also employed in this course, this function is useful for us to review the lecture content and the most important is that it allows us to evaluate our presentation performance so that we can improve ourselves, even after the course."

"One of the feedback from my peer after watching the video is 'I think the audience was not engaged with the presentation",

"The first important thing is to pay attention and enhance eye contact. I have watched the video of my presentation and find this problem as well. The eye contact is inadequate to transfer the information and meaning of what I am talking about. I might do some exercises on it to improve it. Another thing I need to remember is that the time cost of exercise (learning activity). I think it can be achieved by students in 1 min, but it requires around 3 minutes to finish it. So this time cost of exercise also needed to take the students' background knowledge into consideration."

Lesson learnt from self-reflection through Echo360 warrants action plans for improvement which are mostly on the delivery skills. These action plans are characterized by the following feedbacks: 
"From the comments, feedbacks and videos, I think I should practice more about presentation and will do much better next time."

"Besides, eye-contact, facial expression and gestures can be used to enhance presentation."

"What impresses me the most is the presentation skills which we have immediately reflected on our TA sessions"

"Unfortunately, the interaction seems to be not enough. I should have and of course will in the future allocate more time for students to discuss in groups, or design simple games in which the principles of decision making are reflected."

"By reviewing the video, I saw that sometimes my body language was quite 'large' which might not be like a teacher. I should control myself not to make too large movements. Rehearsal is important so that I can review what could be improved and it increases my confidence in delivery."

\section{Discussion Board: Reflective practices through social and instructional interaction}

$\mathrm{Hu} \&$ Fell-Eisenkraft (2003) postulate that Chinese students are silent in classroom because of shyness, fear to make mistakes and lack of confidence in speaking in English. This cultural difference is reflected by two students' reflections:

"Chinese students are much shy in class; most of the students dare not to be the "focus" among peers in the classroom, characteristics of Chinese people contribute to the causes of this situation, but in my opinion, "teaching" custom is also in relation to this reality. Changing people's personality is impossible through one course learning, but changing the "teaching" methodology and differ the classroom culture is possible."

"Engaging the students in activities is another important thing for effective teaching. Chinese students are always afraid of making mistakes. That's the main reason why students don't want to answer questions or participate in activities in class. So how should we change this embarrassing situation?"

"Group discussion also is a good idea for the shy students. They can discuss with their familiar classmates and share their opinions without the need to stand up and face the teacher directly."

As suggested in (Cotterill, et al., 2010), students prefer to discuss social life on the private domain and tend to separate academic social networks from the private social network, SG8001 only provides an ice-breaking online discussion thread on [self introduction] during Week 1 to let course participants know each other. This aligns with the best practice to provide the best possible learning environment through integrating both social and instructional interaction online (Martyn, 2005). Positive feedback is received from students with respect to our practice:

"Creating a relaxed learning environment is important for effective teaching"

"You always made the environment relaxed and we always laughed because of your diverse facial expressions or humorous anecdotes or examples, which engaged students."

"Through discussion board, I shared my opinions on different topics with instructors and other peers. In self-introduction part I clearly demonstrated my personal information, in other discussions such us effective teacher and e-learning, I expressed my 
opinion reflecting from my own experience. I also complete homework -designing ILOS, TLAS and ATS of one session in my research field. I reflect this learning experience by responding to the feedback \& comments received from instructors."

Findings are encouraging in terms of serving as a role model on pedagogical development with respect to utilizing discussion forums, together with other e-learning technologies, in delivering a course, as evidenced by the reflections:

"Through the in-class or out-of-class activities, briefing and debriefing, sharing and feedback, discussion or debate, conclusion are the tools to support me to judge what has been achieved and what has not yet."

"My opinion was that e-learning refers to a self-managed interactive learning platform with the aid of internet technology, and now I firmly believe that it is not only distant learning, but also instant learning as well."

'Though the in class activities and online practice, I gained experience on how to design the efficient learning activities with clear intended learning outcomes. I do think that, the learning atmosphere of this course is very good, everyone is eager to learn and the lecturers always motivate students to engage in the discussion."

\section{Discussion}

The effective use of the two distinctive e-learning technologies (Echo360 and discussion boards) assists the SG8001 teaching team to engage traditionally passive students with positive results. We have found that the e-learning technologies used have evidently improved students' learning outcomes and facilitated reflective practice in teaching and learning. The constructive results are not only limited to students, teaching team members also benefit from it. The collective responses from the course have lead to the support of the three postulations which are presented in the previous section.

The positive impact on students' learning outcomes associated with online engagement is reinforced by the PLS regression analysis on the student online participation data. The computation results suggest that online participation indeed have a significant and positive effect on the students' learning outcomes. Although the results indicate the degree of effectiveness (path coefficient value) is different in the two batches of studies (S01: $\beta=0.294^{*}$ and S02: $\beta=0.415^{* * *}$ ), never-the-less both results show a positive correlation of online participation on learning outcomes. The quantitative computation results from PLS point to the success of our first postulation: Active online participation is positively associated with better achievement of the learning outcomes.

The video capturing system, Echo360, is used as a self-reflection tool in the course. Students can review their in-class presentation performance at home through the system and identify their own weaknesses, with the help of peers and teachers, visually. A number of students commented positively on the effectiveness of the system in the reflective portfolios and in the course feedback. They reported that the system is a very useful e-learning tool for self-reflection and it helped them to improve delivery skills. Besides, captured lectures can always be replayed by students at their convenience to review any missing or difficult to comprehend materials seen in class (as English in not their first language). It helps to improve students' learning without increasing the workload of teaching staffs. On the other hand, Echo360 also provides opportunities to quickly induct new instructors in the SG8001 team teaching environment. New 
instructors can use the system at their convenience to review what was done in the course previously before joining the team. It helps the new instructor to 'feel like virtually being in the classroom', identify patterns, understand the roles, operation and teaching methods and strategies used by the teaching team, discuss it, without relying too heavily on other teaching staffs, to eventually integrate into the teaching team seamlessly. These evidences lead to the support of the second postulation: Echo360 fosters self-reflection in teaching practices.

The use of asynchronous discussion boards in the course effectively facilitates Chinese students to overcome their traditional cultural burden of avoiding being the focal point in public and to freely express their views in a delayed but carefully presented way without worrying too much about their real-time language skills. It also enhances the peer-to-peer interactions among students and allows them to socialize outside the classroom indirectly. The flexible use of discussion boards enables students to combine their social life into their academic world and to create a warm, relax and informative atmosphere for them to learn collectively, reflect individually and discuss academically under teachers' moderation. Students also receive comments and encouragement from both teachers and peers through the discussion boards and develop constructive connections between teachers and students. The feedbacks collected from students evidence the third postulation: Discussion boards integrate social and purposeful instructional interaction facilitates learning and reflective practices.

\section{Conclusions}

Increasing pressure on higher education institutions in terms of both teaching and research tasks has augmented the use of graduate students as teaching assistants. In the past, universities paid little attention to the fact that graduate students with teaching responsibilities in Departments were not systematically supervised and had little or no formal preparation or instruction in how to go about their role. The course described in this study begins to address this critical issue. It also attempts to answer the main question posed at the beginning of the paper by ensuring that the use of video-capture technology and discussion board is 1) engaging and effective, particularly in a) the case of intensive courses taught at off-shore campuses and b) in the case of Chinese Mandarin-speaking postgraduate students teaching in an English Medium of Instruction context and 2) driven by pedagogy and not vice-versa, to prepare them to be more effective teachers, with lifelong learning and reflective skills.

Blended learning technologies, active learning strategies and an outcomes-based approach are now extensively used throughout the world to enable and encourage participation and collaboration (Prieto \& Altmaier, 1994) and are therefore incorporated into this innovative course for first time graduate teaching assistants.

\section{Acknowledgements}

The authors would like to thank all past and present SG8001/SG8001M students for their comments and feedback used in this paper, which greatly improved the manuscript. 


\section{References}

1. Abowd, G. D. (1999). Classroom 2000: An experiment with the instrumentation of a living educational environment. IBM Systems Journal, 38(4).

2. Bomotti, S. S. (1999). Teaching assistant attitudes toward college teaching. The Review of Higher Education, 17, 371-393.

3. Brooks, A. A. R. (1997). Learning Strategies as Learning Inhibitors for Chinese Speakers. Paper presented at the The Annual Meeting of the Teachers of English to Speakers of Other Languages.

4. Brotherton, J. A., \& Abowd, G. D. (2004). Lessons Learned From eClass: Assessing Automated Capture and Access in the Classroom. ACM Transactions on Computer-Human Interaction, 11(2), 121-155.

5. Cheng, C. K., Paré, D. E., Collimore, L.-M., \& Joordens, S. (2011). Assessing the effectiveness of a voluntary online discussion forum on improving students' course performance. Computers and Education, 56(1), 253-261.

6. Cotterill, S., Lowing, K., Cain, K., Lofthouse, R., Mackay, C., McShane, J., et al. (2010). Blogs and e-Portfolios: can they support reflection, evidencing and dialogue in teacher training? Journal of Learning Development in Higher Education, 2(Special Edition: Researching PDP Practice).

7. Flowerdew, L. (1998). A cultural perspective on group work. ELT Journal, 52(4), 325-326.

8. Gan, Z. (2009). "Asian Learners" Re-Examined: An Empirical Study of Language Learning Attitudes, Strategies and Motivation among Mainland Chinese and Hong Kong Students. Journal of Multilingual and Multicultural Development, 30(1), 4158.

9. Gandell, T., Weston, C., Finkelstein, A., \& Weiner, L. (Eds.). (2000). Appropriate use of the web in teaching higher education. Toronto: Canadian Scholar's Press.

10. Gauci, S. A., Dantas, A. M., Williams, D. A., \& Kemm, R. E. (2009). Promoting student-centered active learning in lectures with a personal response system. Advances in Physiology Education, 33(1), 60-71.

11. Harasim, L. M. (1993). Collaborating in cyberspace: using computer conferences as a group learning environment. Interactive Learning Environments, 3, 119-130.

12. Hevner, A. R., March, S. T., Park, J., \& Ram, S. (2004). Design Science in Information Systems Research. MIS Quarterly, 28(1), 75-105.

13. Horton, W. K. (2000). Designing Web-Based Training: How to teach anyone anything anywhere anytime. New York: John Wiley \& Sons.

14. Hu, Y., \& Fell-Eisenkraft, S. (2003). Immigrant Chinese Students' Use of Silence in the Language Arts Classroom: Perceptions, Reflections, and Actions. Teaching \& Learning, 17(2), 55-65.

15. Ku, H., Pan, C., Tsai, M., Tao, Y., \& Cornell, R. (2004). The impact of instructional technology interventions on asian pedagogy. Educational Technology Research and Development, 52(1), 88-92.

16. Kurz, T. L., Batarelo, I., \& Middleton, J.A. (2009). Examining elementary preservice teachers' perspectives concerning curriculum themes for video case integration. Educational Technology Research and Development, 57(4), 461-485. 
17. Llamas-Nistal, M., Caeiro-Rodríguez, M., \& Castro, M. (forthcoming). Use of ELearning Functionalities and Standards: The Spanish Case. IEEE Transactions on Education, 10 pages.

18. Malone, T. W., \& Lepper, M. R. (1987). Making Learning Fun: A Taxonomy of Intrinsic Motivations for Learning. In R. E. Snow \& M. J. Farr (Eds.), Aptitude, Learning and Instruction (Vol. 3, pp. 223-254). New Jersey: Lawrence Erlbaum Associates.

19. Mark, K. P., \& Vogel, D. (2009). Technology Support for Engagement Retention: The Case of BackPack. Knowledge Management \& E-Learning: An International Journal, 1(3), 163-179.

20. Mark, K. P., Vogel, D. R., \& Wong, E. Y. W. (2010). Developing Learning System Continuance with Teachers and Students: Case Study of the Echo360 Lecture Capturing System. Paper presented at the Pacific Asia Conference on Information Systems 2010 (PACIS 2010), Taipei, Taiwan.

21. Martyn, M. A. (2005). Using Interaction in Online Discussion Boards: Successfully fostering interaction in online courses requires incorporating both instructional and social types of interaction in discussion boards. Educause Quarterly, 28(4), 61-62.

22. Marxa, R. W., Blumenfeld, P. C., Krajcik, J. S., \& Soloway, E. (1998). New technologies for teacher professional development. Teaching and Teacher Education, 14(1), 33-52.

23. Mazzolini, M., \& Maddison, S. (2003). Sage, guide or ghost? The effect of instructor intervention on student participation in online discussion forums. Computers and Education, 40(3), 237-253.

24. Mazzolini, M., \& Maddison, S. (2007). When to jump in: The role of the instructor in online discussion forums. Computers and Education, 49(2), 193-213.

25. Menges, R. L., \& Rando, W. C. (1989). What are your assumptions? Improving instruction by examining theories. College Teaching, 37, 54-60.

26. Ortiz de Guinea, A., \& Markus, M. L. (2009). Why Break The Habit of a Lifetime? Rethinking the Roles of Intention, Habit, and Emotion in Continuing Information Technology Use. MIS Quarterly, 33(3), 433-444.

27. Prieto, L. R., \& Altmaier, E. M. (1994). The relationship of prior training and previous teaching experience to self-efficacy among graduate teaching assistants. Research in Higher Education, 35(4), 481-497.

28. Richardson, J. C., \& Swan, K. (2003). Examining social presence in online courses in relation to students' perceived learning and satisfaction. Journal of Asynchronous Learning Networks, 7(1), 68-88.

29. Rubin, D. (1993). The other half of international teaching assistant training: Classroom communication workshops for international students. Innovative Higher Education, 17(3), 183-193.

30. Tsang, H. M., Mark, K. P., \& Vogel, D. R. (2010). Postgraduate Student Learning System Continuance: a Case Study of Echo360 Lecture Capturing System. Paper presented at the Cross Straits Information Management Conference, Hong Kong.

31. Watt, S., \& Jones, J. S. (2010). Let's look inside: Doing participant observation. In J. S. Jones \& S. Watt (Eds.), Ethnography in Social Science Practice (pp. 107-125). London: Routledge.

32. Williams, S., \& Pury, C. (2002). Student Attitudes Toward and Participation In Electronic Discussions. International Journal of Educational Technology, 3. 
33. Yeh, H.-T. (2005). The use of instructor's feedback and grading in enhancing students' participation in asynchronous online discussion Paper presented at the Fifth IEEE International Conference on Advanced Learning Technologies, Kaohsiung, Taiwan.

34. Yip, W., \& Mark, K. P. (2007). Evaluation of Student and Tutor Perceptions of Peer Tutoring Communities Supported by Web Technology. In G. Wolfson (Ed.), Proceedings of the International Conference on Information Communication Technologies in Education (pp. 235-241). Heraklion: UCFV Press.

35. Yoshida, T., Tada, K., \& Hangai, S. (2005). Development and Evaluation of a Keyword-Accessible Lecture Video Player. International Journal of Distance Education Technologies, 3(4), 51-61. 